\title{
Art andCommunication: Conflict and Reconstruction for Autonomous Identity
}

\section{Umit Inatci, Eastern Mediterranean University, North Cyprus}

\begin{abstract}
:
This essay focuses on the relational embodiment of art \& communication that, it is fair to say, that it implicates problematic crossroads between memory and contemplation. If we see art as, I believe one should, as inter-subjective communication emanating from the primary necessities, which in turn arise from ontological concerns then we should pay attention to the relationship between art and communication. This essay is structured in three pats dealing with different instinctive and notional aspects of the subject. 1/ Attention-Intention Relation.2/ Inside-Outside-Presence.3/ Memory-Visual Culture-Notion.
\end{abstract}

Keywords: Art, Communication, Visual Culture, Memory, Presence. 


\section{Introduction}

If we think that communication is linked with a desire of contemplation, which remains one of the more basic intentions of doing art, then we can relate art to the idea of attention as well as the desire of being relative to everything surrounding us as phenomena of the external world. The fact that human beings are alive and physically and intellectually active is a sign that they are present in and pay attention to the universe around them. To be present in a specific space and time creates a feeling of unity. In other words, it creates an entity. In this sense the concepts inside and outside become the keywords for inter-subjective communication between oneself and the other. Certainly this is not enough unless one acts consciously and having the necessary knowledge and experience which can be said to cultivate the right instincts in art related matters. In this case memory and collective memory are naturally shaped by a visual culture involving artistic elements.

\section{Attention-Intention-Relation}

When we fix our attention on something we get in touch with everything that is related to that particular thing. The attention we turn on it allows the gaining of knowledge about it. This means internalizing the reality that surrounds us. At first, our relation with things depends on the information transferred from subject to object. Afterwards and as this relation evolves into a process of interpretation it becomes subjective. When that happens the thing is not a thing anymore, it is whatever we make of it through our interpretation of it. Unlike relations with human beings, the relation between subject andobject, which we establish with things, transforms into a meaning centered process when transferred into the artistic field.

The shaping of a relation [fed by attention's insistence] through intention stimulates a design of a desire or will. This is not perceivable without understanding the codes of communication and before it transmutes into actual communication through some mechanism. Communication has a metalinguistic meaning structure, which includes apart from the message, perceptibility. Sometimes a meaning can be veiled or hidden and at other times might have disclosing features. If art is to draw attention it must succeed to visually establish a connection between the thought (the Platonic Form) and the intention (intentio-Kant).

To intend, one must have an aim or target. (Telos-Aristotle). Here is where the design of desire comes in. Making clear what we want and this being turned into an impact element 
depend on which image, indicator and codes we construct. This language is the only tool of subjective relation that will be established between the other and myself. By activating its own aesthetic codes here the art through indication, form and image contributes to the formation of a collective memory. What art exposes, other than the daily mass media instruments is the existence of a creative language representing the autonomous entity of the individual.

The acquiring of autonomy by the individual through art has allowed a formal language with aesthetic codes to come into being in our lives. The iconographic communication style that was used for "faith propaganda" and its expansion attains freer meaning and narrative space with the Renaissance. The rejection of the classical rules in art as a consequence of modernism, already beginning to be prevalent in Romanticism, allowed a more emancipatory nature to the artist's presence. In this environment, the inter-subjective relation style that art has established undergoes a change not over the stories told but over the nature of perception itself. The most significant change in this process is the one related to the perception of time and space introduced by Impressionism. The artist no longer searched just for the intersubjective relation but made it possible for to arise from a relation with the physical environment.

\section{Inside-Outside-Presence}

Giorgio Agamben in his book "Aperto" says that the experience of being outdoors is different for humans and animals. The physical environment that we refer as "outside" is really the equivalent of being “ inside" for an animal. The Impressionists [by going outside the atelier] and observing the impact that the moving daylight instead of the stationary light has on the perception of objects was not actually going outside but was going inside, which meant returning back to nature. "Sunset" was nothing but an impression; since it was the earth that was moving not the sun. Perhaps it was the first step taken in order to prove Galilei's scientific discovery through art.

The return action of art and the artist to nature was inter alia a manifestation of communicating with the physical environment. Art was now occupied with conveying both the ways of nature and the relation between man and nature. Being outside led to the discretization of the metaphysical forms of thinking which aggrandize/exalt the supernatural 
or superhuman. Art's interaction with the outside, and its transmittance of nature and the nature of human behavior through impressions to the other praxis was going to bring the end of the sharp separation between the outside and the inside. The communication was now actualized by producing aesthetic codes directly connected with the ways of nature instead of images.

In Cubism, the separation between interior and exterior was eliminated by the atmospheric integrity prevalent in the cubist paintings. Looking at an object from multiple perspectives and providing the perception of a fourth dimension created another formality. Time was represented as a concept that can be perceived like space. From Joseph Beuys to the artists of Arte Povera outside was now, Agamben expressed as inside, transformed into the real world of human life and experience.

Artistic communication could now find its objective basis in objects used in everyday life. Not only humans but objects as well could be contemplated within an ontological context and objects as well as man had something to say. Objects could also be transformed into images of time and space even into tools of a ritual man-nature relation, the kind of relation that we associate with ancient religions. Here we can now talk about visual culture and collective memory; and of course about the notion, which fosters the relation between the visual and memory.

\section{Memory-Visual Culture-Notion}

We can make sense of the influence of visual culture, which is in fact more influential than either written or oral culture, in terms of thoughts reflected in behavior. This way we come to understand how influential visual culture most by means of cultural anthropology. The most effective component that gives shape to human behavior is the notion that shapes memory. At this point we can talk about more than mere aesthetic codes. We can talk equally about social and institutional codes. We see that the visualization used in the methods of representation of political, religious or civil institutions can be so influential so as to lead even to commitment to images. We see that besides the mass communication channels the coterie centrist mass formations applies visual perception-based hegemonic initiatives. Legends created by exalting a visual image, an object or a course of action can be transformed into justifications to which the masses can be devoted. 
The response of art against this object and idol fetishism is to view this situation with ironic indifference. Irony, however, can be a form of criticism that the dominant institutions cannot tolerate. Various role model images, which are activated to blunt the response capabilities of the people, pave the way to a sociological disintegration. Individuals dispersed and fragmented among the options want to be visible not through their own behavior but with through role model of their choice. In this case, the individual's ability to show an existential response declines.People's wanting to be remembered through what they remember is the result of such suppression. In this case, collective memory can be turned into a mechanism of passivity.

The identification motive arising from the mystical relation people establish with the idols and the pleasure they get out of this reduces the individuals' appetite of being themselves. In this case, it wouldn't be hard to create an obedient mass from a mass, which tends to uniformity. If art could transform its communication modality into a subversive ontology the relation between society and the individual could be restored to health. The memory fed by the visual culture comes into play as an upper consciousness in communication medias via notion. The situation that art as a meta-language tries to comprehend and convey clashes with the constructed upper consciousness in question. Memory, visual culture and notion when taken within the scope of art and communication need to be approached through the framework of social psychology and cultural anthropology.

\section{Conclusion}

Especially when considering the multi-disciplined and transitional character of contemporary art we can say that more than being moving on parallel courses, communication intersect. The visual culture that flows in all kinds of mass media and social media with a speed and density one cannot keep up with, multiplies the understanding of a monistic culture and renders the masses uniform. This is done by constantly projecting images and behavior patterns that are apparently different but in substance similar, for individuals to identify with. For art to transform itself into a defensive reflex protecting the individual's autonomous entity against this situation, getting rid of the vicious capitalist control and management of the art market is an absolute necessity.Art envisaging conflict and reconstruction can become a haven for man who shows the ability to return to nature. 
Attention, intention, relation, in, out, the current state of being, memory, visual culture and the notion...all these concepts indicate the necessity of reconsidering the way man communicates with man, with nature and with himself. 